\title{
Transformaciones ambientales y producción agro- forestal: El Gran Chaco Argentino en el siglo XX
}

Environmental changes and agro-forest produccion: the Argentina Gran Chaco in theXX century

Transformaçōes ambientais e produção agroflorestal: 0 Grande Chaco argentino no século XX

Adrián Gustavo Zarrilli*

\section{Resumen}

En tiempos de la independencia hacia principios del siglo XIX, había en Argentina 160 millones de hectáreas de bosques, montes y selvas originales. En menos de dos siglos el país perdió más de dos tercios de su patrimonio forestal autóctono. Hoy le quedan menos 33 millones de hectáreas forestales. La explotación de la esta extraordinaria riqueza forestal Argentina, es el punto de partida de este análisis que se propone trazar un cuadro interpretativo - desde una perspectiva histórico-ambiental - de la evolución de las transformaciones histórico-ambientales de la región del Gran Chaco Argentino en el siglo XX, sus ciclos productivos y su relación con la expansión del modelo de agricultura capitalista. Nuestro objetivo central es, entonces, el estudio histórico-ambiental de este proceso de transformación de esta región, en el contexto de su incorporación al merca- do y la relación que se establece entre este proceso de deforestación y la expansión de la frontera agrícola, su transformación artificial, conflictos, grados de especialización, racionalidad, interacción y el deterioro progresivo de los mismos.

Palabras claves: Historia. Ambiente. Gran Chaco.

\section{El Gran Chaco Argentino - Un territorio transformado}

El espacio geográfico sobre el que se desarrolla la explotación forestal mas intensa de la Argentina esta constituida por el área de la llamada llanura Chaco - Pam-

\footnotetext{
Doctor en Historia (Universidad Nacional de La Plata). Investigador del CONICET y Centro de Estudios de la Argentina Rural, Universidad Nacional de Quilmes, Argentina. E-mail: azarrilli@unq.edu.ar

Recebido em 02/03/2016 - Aprovado em 20/03/2016 http://dx.doi.org/10.5335/hdtv.16n.1.6253
} 
peana. Para la Argentina esta región abarca 60 millones de has $\left(600.000 \mathrm{~km}^{2}\right)$, y ocupa el 22\% de la superficie continental del país. Es su región forestal más grande. El Chaco Argentino involucra a diez provincias, abarcando la totalidad de las Provincias de Formosa, Chaco y Santiago del Estero, y partes sustanciales del Norte de Santa Fe y San Luis, Este de Salta, Tucumán, Catamarca y La Rioja, y Norte y Oeste de Córdoba. A pesar de que la Argentina se estructuró económicamente a partir de la producción agropecuaria en la Pampa Húmeda, la actividad forestal constituyó desde siempre un importante complemento del desarrollo generado por las actividades agrícolas-ganaderas. La demanda nacional de maderas para la construcción y como combustible creció significativamente a partir del aumento poblacional producido a mediados del siglo XIX principalmente en la región pampeana. Esta situación llevó a la actividad extractiva en los territorios forestales de las áreas tropicales y subtropicales. Al uso doméstico de la madera, se sumó la demanda de las nacientes industrias que progresivamente se reproducían y se volvían más complejas. El caso más emblemático en lo que refiere a explotación forestal desmedida es el del quebracho colorado en la región chaqueña. Entre las principales causas de la explotación de la madera del quebracho colorado chaqueño estaba la expansión de las vías férreas. Esto produjo, por un lado, un consumo obligado de esa y otras maderas duras para armar los durmientes de dichas vías, para producir el carbón que moviera las locomotoras y otros variados usos. Otro factor para que se arrasara con los quebrachales de gran parte del
Parque Chaqueño fue la extracción de tanino para el para el curtido del cuero.

Mapa 1 - Gran Chaco

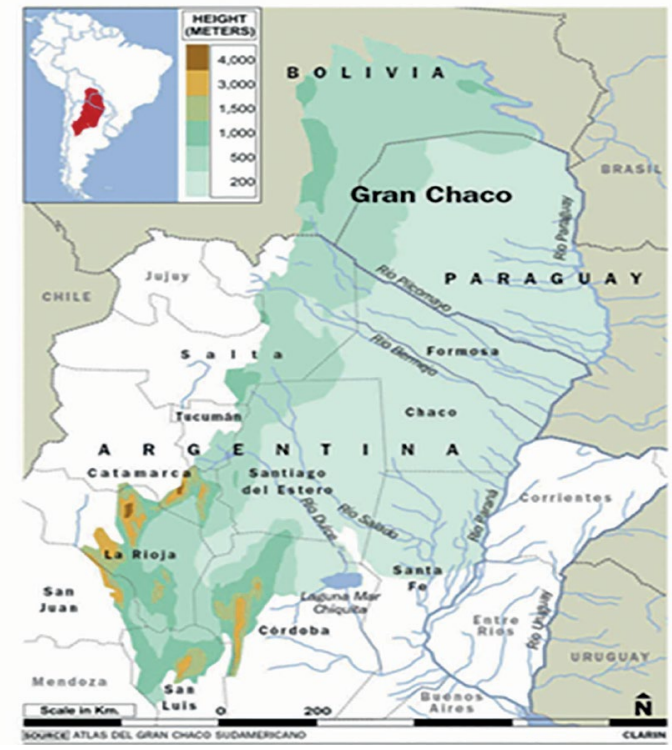

Fuente: Atlas de Gran Chaco Sudamericano.

La explotación de la riqueza forestal Estimaciones sobre la pérdida del bosque nativo

El primer dato sostenido con autoridad que se conoce acerca de la superficie forestal de la Argentina, existe en un proyecto de ley forestal presentado a la Cámara de Diputados en el año 1915 y en cuyo estudio participó entre otros el botánico, Carlos Spegazzini. En el se mencionaba una superficie boscosa de 106.888.400 has, algo así como el 38.6\% del territorio argentino. Desde ya estas cifras no hablan solo de bosques maderables, sino también de asociaciones leñosas espontáneas, arbóreas y arbustivas (es decir de tierras forestales). Tomando en cuenta este dato, nada se opone a que sea aceptada esa primera información estadística, tal como sostiene 
Domingo Cozzo uno de los principales expertos forestales de la Argentina.

Desde aquella primera cifra del año 1915, pasaron muchos años hasta hallar nuevas estimaciones estadísticas, casi siempre contradictorias entre si y de difícil estimación sobre su calidad. Así, en el Almanaque anual del Ministerio de Agricultura de la Nación del año 1938, figura en un gráfico de la Dirección de Economía Rural y Estadísticas una área boscosa de 50.000 .000 millones de hectáreas entre montes y bosques, pero al año siguiente en la misma publicación y sin ninguna clase de explicación se transformaba su estimación en una cifra muy diferente, 89.000.000 de has (COZZO, 1967).

A partir de aquel primer proyecto de ley forestal hubo otros muchos mas, y en cada ocasión, los técnicos y funcionarios desarrollaron diferentes estimaciones sobre la superficie forestal argentina; así en el de 1938 figuraba una extensión de 48.570 .000 has. En 1937, por ejemplo, el ingeniero Isaac Grunberg hablaba de una superficie boscosa de solamente 40.000 .000 de has. Esta cifra es inferior a su vez a la que se establecía en el capítulo de Acción Forestal del $2^{\circ}$ Plan Quinquenal del gobierno de Perón en el año 1953, donde se contabilizaban 60.000 .000 de has. A su vez varios técnicos forestales argentinos emitieron en su tiempo otras estimaciones. A su vez estimación confiable sobre la superficie efectiva de bosque de la República Argentina corresponde al Censo Nacional Agropecuario del año 1937 que indica una superficie de 37.535.306 has de bosques nativos para ese año. A partir de entonces, las estimaciones realizadas muestran una disminución notable de la superficie boscosa. Para el año 1943 el destacado forestal argentino Ing. Franco Devoto hablaba de 50.000.000 has de bosques nativos (ZARRILLI, 2007).

En el mencionado proyecto de 1915 existía también un cálculo del área forestal para cada provincia argentina, que pese al tiempo transcurrido y su conformación con las informaciones posteriores, puede servir para apreciar el carácter forestal de cada uno de estos estados y el retroceso de sus.

Cuadro 1 - Superficie de bosque nativo por provincia, 1915-1956

\begin{tabular}{|l|r|r|}
\hline \multicolumn{1}{|c|}{ Provincia } & $\begin{array}{r}\text { Superficie boscosa } \\
\text { (en has) } 1915\end{array}$ & $\begin{array}{r}\text { Superficie boscosa } \\
\text { (en has) } 1956\end{array}$ \\
\hline Buenos Aires & 169.400 & 100.000 \\
Entre Ríos & 4.930 .000 & 1.000 .000 \\
Santa Fe & 5.890 .000 & 3.000 .000 \\
Córdoba & 13.800 .000 & 4.000 .000 \\
Tucumán & 1.980 .000 & 1.200 .000 \\
Corrientes & 4.725 .000 & 2.000 .000 \\
Mendoza & 7.740 .000 & 500.000 \\
Jujuy & 1.824 .000 & 1.000 .000 \\
Salta & 10.700 .000 & 5.000 .000 \\
Santiago del Estero & 10.700 .000 & 6.000 .000 \\
Catamarca & 5.150 .000 & 3.500 .000 \\
La Rioja & 7.790 .000 & 4.000 .000 \\
San Juan & 6.180 .000 & 1.500 .000 \\
San Luis & 6.090 .000 & 2.500 .000 \\
Formosa & 4.020 .000 & 4.000 .000 \\
Chaco & 8.250 .000 & 6.500 .000 \\
Misiones & 2.570 .000 & 2.300 .000 \\
La Pampa* & 1.915 .000 & 8.500 .000 \\
Neuquén & 300.000 & 170.000 \\
Río Negro & 130.000 & 100.000 \\
Chubut & 1.000 .0000 & 1.000 .000 \\
Santa Cruz & 200.000 & 70.000 \\
Tierra del Fuego & 835.000 & 700.000 \\
Total & 105.888 .400 & 58.640 .000 \\
\hline
\end{tabular}

* Los datos del Territorio Nacional de La Pampa habían sido minimizados en el estimado de 1915.

Fuente: Cozzo (1967, p. 15).

De estas cifras algunas parecen estar magnificadas, como es por ejemplo el caso de las provincias de Córdoba, Catamarca, La Rioja, San Juan y Mendoza, aunque es probable que estas distorsiones estén referidas a las formaciones leñosas del tipo "monte" que 
muchas veces son improductivas, excepto para la leña. En el caso del Territorio Nacional de La Pampa y de la provincia de San Luis, los caldenales se redujeron de 15.000 .000 de has a no mas de 2.000 .000 en menos de 50 años. Allí se produjo como consecuencia del proceso deforestador un avance notorio de los médanos y de una vegetación arbustiva sin un inmediato valor económico.

Para el mismo período en Entre Ríos, la famosa "selva" de Montiel de ñandubay, espinillos, etc., que antiguamente cubría gran parte del noroeste de la provincia, quedó reducida a pequeños manchones de bajos y muy modestos restos de aquella riqueza forestal. En Córdoba desaparecieron los montes leñeros del norte ante el abrumador corte de leña y carbón para las ciudades circundantes, actividad que luego se traslado a Santiago del Estero, con similares resultados o aun peores de impacto socio-ambiental. A partir de la Segunda Guerra Mundial, cuando la Argentina no contó con los suministros foráneos de combustibles minerales, fueron en mayor parte la leña y el carbón vegetal los que los sustituyeron, pero a costa de talar anualmente no menos de 1.000 .000 de has (ZARRILLI, 2007).

Los bosques de la Provincia de Misiones fueron los primeros en ser cortados para proveer maderas en los mercados de Buenos Aires, por la calidad de ellas (especies de "ley" cedro-lapacho-incienso) y la facilidad de transporte en "jangadas" aprovechando el descenso de las aguas del Paraná. Que ya se cortaban en demasía y sin control, lo demuestran las intenciones de la primer ley forestal argentina hecha sancionar par el Presidente Avellaneda en 1880 (la ley No 1054) antes que se estableciera una oficina fiscal de bosques; impone normas para reglar y reponer las cortas, e incluso los desmontes que ya se hacían con fines de colonizaciones. Las sucesivas perdidas de bosques en esta provincia fueron notorias de $26.100 \mathrm{~km} 2$ en sus orígenes (87\% territorial local) a 20.000 en 1960 (70\%), 12.630 en 1974 (42\%), y 10.000 en 1983 (36\%), Con una tasa anual de $200 \mathrm{~km} 2$ desmontadas. En el término de poco mas de un siglo sus bosques se redujeron a un tercio, degradados en su gran mayoría además de unos $8.000 \mathrm{~km} 2$ de "capueras" ("monte volteado"), vegetaciones arbustivas-subarboreas que aparecen espontáneamente en terrenos ex-selvas desmontados y abandonados ("barbechos forestales").

Para el mismo período los bosques de quebracho colorado del este fueron eliminados casi totalmente de Santa Fe, centro inicial principal de la industria de su extracto tánico, con un panorama similar en los Territorios Nacionales de Chaco y Formosa. Para 1940 una sola empresa taninera en sus principales establecimientos industriales consumía diariamente mas de 1300 toneladas de rollizos de esa madera, lo que significaba unas 400.000 ton al año, significando la exterminación por esta sola corta de 16.000 has de quebrachales. La estimación técnica es que hasta mediados de la década de 1940, toda la industria taninera había utilizado la madera de unos 30.000.000 de árboles que equivalían a la corta de unas 2.500 .000 de has. Ese mismo informe técnico señalaba que si se sumaran las toneladas de quebracho colorado utilizadas para producir su extracto tánico, mas las empleadas para elaborar durmientes de ferrocarril, postes, etc., mas las quemadas 
en forma de leña y carbón se obtendría un total que se calcula no inferior a 350.000 .000 de tn (equivalentes en promedio a la misma cantidad de árboles de esa especie) y toda esa corta se produjo en unos 75 años, habiéndose despoblado así unas 10.000.000 de has de estos bosques. Solamente en Santiago del Estero en la primera mitad del siglo XX se cortaron 200.000.000 árboles de quebracho colorado y blanco (TORTORELLI, 1956).

El retroceso de la extensión territorial de los bosques y montes fue más fuerte en el área ocupada por las formaciones leñosas del centro, región andina y las del nordeste, es decir, las que estaban mas expuestas a las cortas para el combustible que requerían las poblaciones cercanas y las líneas de ferrocarril. Cada localidad o estación ferroviaria fueron centros de constante y acentuado desmonte, primero de las existencias en sus alrededores a la manera de ondas concéntricas y luego en las zonas más lejanas.

Las dificultades de transporte por falta de caminos o por los altos fletes, y la terminación de la explotación dentro de una misma propiedad, obligó en muchos casos a volver a cortar los bosques ya explotados, este "repaso" o "rehache" hecho dos o tres veces, terminó por agotar el bosque de sus mejores árboles y los redujo a meras masas sin valor comercial inmediato; en otros lugares, el "rehache" significó terminar definitivamente con el monte productivo, aun como leña, dejando en su lugar una vegetación baja, enmarañada, como producto del rebrote de especies nuevas, netamente heliófilas y sin importancia comercial, como sucedió con los montes y bosques de Santiago del Estero que desde mediados del siglo XX son simplemente "fachinales", que equivale tanto como a vegetación "sucia" y sin valor (TORTORELLI, 1956).

Recién para el año 1956, se realiza una nueva estimación, tal vez una de las mas completas hasta la década de 1980, la misma se debió a las deliberaciones técnicas efectuadas en Buenos Aires, a partir del acuerdo entre la CEPAL y el gobierno argentino. En la misma se estudió la superficie ocupada por vegetación forestal espontánea. La delimitación entre lo era superficie de tierras forestales y de bosques productivos, era una necesidad a fin de poder comprender mejor el estado de la Argentina forestal (para estas estimaciones ver Cuadro $\mathrm{N}^{\circ} 1$ ). Las notables diferencias en las estimaciones forestales de las diversas fuentes, derivan del hecho de considerar unas veces a las tierras forestales como tales y otras solamente a los bosques productivos. Así con las tierras forestales se consideraron en general las áreas ocupadas por cualquier tipo de vegetación leñosa, incluidos los matorrales sin mayor producción aprovechable, Los bosques productivos es en cambo la vegetación leñosa capaz de suministrar madera aserrable y/o combustibles vegetales; su extensión superficial, comprendida siempre dentro del concepto de "tierras forestales" es la de los bosques propiamente dichos. Hacia principios de la década de 1960 las tierras forestales giraban alrededor de las 50.000 .000 de has pero de ellas apenas 27.000.000 eran de bosques realmente maderables (ZARRILLI, 2007).

En este contexto y a lo largo de los años se ha señalado a la expansión agrícola como factor común en casi todos los estudios sobre la deforestación. De hecho, gran parte del aumento de la producción de alimentos se ha lle- 
vado a cabo a costa de centenares de millones de hectáreas de bosque. No hay estimaciones sólidas sobre la superficie de tierras agrícolas y de pastoreo que originalmente estaban cubiertas de bosques, pero lo cierto es que una gran proporción de éstos fueron talados para dar lugar a actividades agrícola-ganaderas.

Además del fenómeno de la deforestación existe otro proceso de deterioro del recurso: la degradación, que consiste en la pérdida de biomasa y da como resultado un bosque empobrecido. Existen claras evidencias de que la pérdida de biomasa en las masas forestales tropicales tiene lugar con una tasa significativamente más elevada que la pérdida de superficie debida a la deforestación. Sin embargo, al ser un proceso menos impactante a simple vista no recibe la atención que merece. Ante este estado de cosas, la Deforestación y Degradación de las masas forestales constituye una de las mayores amenazas para el equilibrio ecológico de todo el planeta, al que hemos colocado en una verdadera situación de emergencia.

A su vez los montes boscosos y/o entremezclados con arbustos de la llanura chaqueña (el llamado "parque chaqueño") han sido probablemente, los más cortados y desmontados, proveyendo sus maderas duras para durmientes ferrocarrileros, materia prima para la extracción de taninos (quebracho colorado), leña fuerte, postes, y sus terrenos para cultivos de algodón, cereales, además de una ganadería subtropical. Esta dinámica de destrucción y transformación en nuevos sistemas de matorrales-fachinales en el sector argentino del Gran Chaco, constituye una de las más grandes catástrofes ecológicas ocurridas en las llanuras ameri- canas ya que sus bosques cubrían 1.000.000 $\mathrm{km}^{2}$. Aquellos autores indican que los daños graves ocurrieron en las márgenes orientales más que en sus espacios interiores, quedando unos $40.000 \mathrm{~km}^{2}$ de bosques áridos, degradados, con sus suelos sobrepastoreados y con creciente proceso de erosión hídrica en épocas de mayores lluvias. Además las sucesiones de lluvias y fuegos, anteriores a las ocupaciones humanas, generaban flujos alternados de pastizales y arbustales, pero la excesiva intervención antropogénica los alteró transformándolos en "peladares": paisajes desnudos o con algunos arbustos sin ningún valor leñoso-forrajero, provocando incluso la desaparición de valiosa fauna silvestre. En 50 años se extrajeron unos 350 millones de toneladas de rollizos de quebrachos-urundailes (COZZO, 1971).

En los años 60 y 70 del siglo XX la presión del avance agropecuario, primero desmontando del este hacia el oeste (Chaco-Santa Fe-Santiago del Estero-Formosa) y también del opuesto lado, oeste hacia el centro (Salta- Tucumán), ha sido incontenible y hasta apoyada con medidas fiscales; un ejemplo es el operativo colonización del chaco boscoso llamado "impenetrable" de $40.000 \mathrm{~km}^{2}$ iniciado par el Gobierno provincial en 1977, hasta entonces una región poco perturbada justamente par carecer de buenas fuentes hídricas. Esta provincia desde antes mostró vocación de expandirse a expensas de sus montes: en 1965 creó el "Instituto del desmonte": un organismo que claramente tenia un objetivo "contra natura", llamativamente organizado para continuar con una política de marcado carácter destructivo de los recursos forestales. Hacia principios de la década de 1980 para el Chaco 
santiagueño se reseñó que de una superficie de $98.000 \mathrm{~km}^{2}$ (= 70\% provincial) quedaban solo 7.300 aprovechables $(=7 \%)$, el resto esta degradado o desaparecido; en esta provincia y hasta 1941 se habían cortado 150 millones de árboles de quebracho colorado, además de algarrobos y otras especies valiosas madereras. También hay que señalar como otra de las mayores devastaciones de este recurso al proceso que tuvo lugar entre las dos grandes guerras mundiales cuando se desmontaron no menos de 10.000 .000 has; lo que significó proveer el $50 \%$ de las necesidades energéticas del país cuando en situaciones normales participaban del 20\% (ZARRILLI, 2007).

En ciertas situaciones muchos bosques y montes exterminados se recobraban con nuevas vegetaciones leñosas que reaparecen en sus mismos terrenos y que, si no eran vueltos a cortar podían, luego de procesos sucesionales autocompetitivos, generar nuevas formaciones bascosas de protección y productividad madereras; como lo eran los denominados barbechos forestales y también "bosques secundarios".

A estas recuperaciones territoriales se les agregan superficies que no contaban con plenas cubiertas leñosas (o dispersos y abiertos montes bajos) y que son colonizadas par especies leñosas que no existían antes; el ejemplo mas notable de estas nuevas vegetaciones, en Argentina y Paraguay, es el "vinal" (Prosopis ruscifolia); de antaño solo un elemento florístico de comunidades en el oeste de Formosa, comenzó desde principios de este siglo un avance ocupacional hacia el este semiárido y húmedo de esta misma provincia, el Chaco y Santiago del Estero, llevados sus frutos-semillas par los rodeos de vacunos hacia los mercados y con las aguas aluvionales de los ríos regionales. Los "vinalares" cubrían $80.000 \mathrm{~km}^{2}$; se supone que ya son mas de 100.000 , el 60\% en terrenos de Formosa, $15 \%$ del Chaco y $25 \%$ entre Santiago del Estero y Salta (MORELLO; PENGUE; RODRIGUEZ, 2005, p. 11).

\section{El ciclo algodonero}

La combinación de factores políticos internos y externos, con un régimen de tenencia de la tierra favorable a la inmigración europea, la necesidad de asegurar territorios para implantar una cultura extractivista ligada a parámetros exclusivos del modelo agro exportador y la exacta mezcla entre declinación del ciclo taninero con la presencia de una mano de obra muy fácilmente explotable, en condiciones de extrema vulnerabilidad social detonaron las condiciones para la aparición del nuevo ciclo: el algodonero, hacia 1920. Favorecido entre otros factores por la situación internacional y la crisis productiva por invasión del picudo algodonero en Estados Unidos. La inmigración hacia el desierto verde del Chaco en un contexto de Guerra Mundial y necesidad de abastecimiento a la industria textil europea, hacen que aparezca de nuevo, en otra porción del territorio chaqueño, un modelo de producción extractivista primario, basado en la oportunidad algodonera, ligada a la consolidación de una economía regional vinculada marginalmente a la región central pampeana, que termina resultando un esquema insostenible, por sus efectos sociales y ambientales directos.

En el ámbito regional, la planicie central chaqueña es desde siempre el área algo- 
donera por excelencia, alrededor de la cual se lleva adelante el monocultivo (Quitilipi - Sáenz Peña - Villa Angela y Las Breñas) coincidiendo con el espacio donde los promedios de lluvias oscilan entre los $700 \mathrm{y}$ $1000 \mathrm{~mm}$ anuales, degradándose dicha área hacia el occidente, fundamentalmente a causa del incremento de la aridez. Este escenario ha sido básicamente monoproductor, ya que allí las opciones de diversificación que son específicas de las prácticas mas tradicionales de cultivos anuales, son llevadas adelante por los agricultores en función de las dimensiones físicas de sus explotaciones y de las perspectivas de la demanda interna y de los precios relativos. La mayor disponibilidad de tierra posibilita un contexto de mayor participación, con una un incremento en la integración social y comercial, lo que alienta a mayores posibilidades de progreso. Mientras pequeños agricultores chaqueños - con explotaciones menores a 50 hectáreas - comparten una serie de rasgos negativos de diversa especie (dependencia del trabajo familiar en condiciones precarias de tenencia de la tierra, casi nulas posibilidades de acceso al crédito accesible, extrema vulnerabilidad a los fenómenos meteorológicos y dependencia en relación a la intermediación comercial; la situación de los agricultores con explotaciones de mayor envergadura las que históricamente no constituyen un porcentaje elevado en la estructura agraria provincial, siempre fue más desahogada por contar con una mayor extensión de tierra que les posibilita un margen más amplio de diversificación en su manejo productivo (VALENZUELA, 2005).

El riel, la mano de obra expulsada del obraje, las exigencias de la ocupación del es- pacio, la deforestación, la apertura de nuevos espacios para la producción agrícola, detonan en las áreas agro-ecológicas del centro-oeste chaqueño, un sistema productivo que se reorganiza en todo ese espacio, causando un impacto decisivo en todo el ciclo biológico del área afectada por estos procesos. El cultivo del algodón - por su parte - provoca una reacción en cadena de poblamiento con cierta permanencia del poblador en el territorio.

Para fijar esta estructura social resulta determinante el auge de la producción agrícola, incentivada por empresas exportadoras y el gobierno central a partir de 1920. Se suma a esa coyuntura el crecimiento de los precios y la demanda en el mercado internacional durante la Primera Guerra Mundial. El primer crecimiento algodonero destinado a la exportación se concentra principalmente en el Chaco. Formosa se integra al mismo recién en la etapa abierta con posterioridad a la crisis de los años 30, cuando el acelerado proceso de urbanización y transferencia de ingresos que vive el país sustituye a la demanda internacional por una creciente capacidad de consumo interno durante toda esta etapa. Las políticas públicas juegan un papel preponderante en la conformación del área. Por un lado, las leyes de colonización reflejan el interés de poblar una zona marginal de escaso valor rentístico, a pesar de lo cual son combatidas y muchas veces desnaturalizadas por los grupos ligados a la explotación forestal que buscan mantener la libre disposición de tierras fiscales para su actividad (VALENZUELA, 2000, p. 11-31).

El problema productivo posterior a la recolección comprende dos momentos diferentes: el desmote y prensado de la semilla, 
así como el enfardado del algodón en las desmotadoras y aceiterías locales. A su vez, el algodón enfardado se embarca para Buenos Aires, donde se localizan el $85 \%$ de las fábricas que realizan el hilado y los tejidos de esta fibra. En consecuencia la industria vinculada al algodón se disocia. EL Chaco sólo cuenta con 130 desmotadoras y aceiterías; de ellas, algunas funcionan Bajo el régimen de cooperativas, y otras SON de gestión estatal o privada. Las fábricas de textiles locales soncas y de producción limitada (ADÁMOLI; TORRELLA; GINZBURG, 2004).

Gráfico 1 - Superficie: Hectáreas con Algodón - Campañas 1909/10 a 1948/49

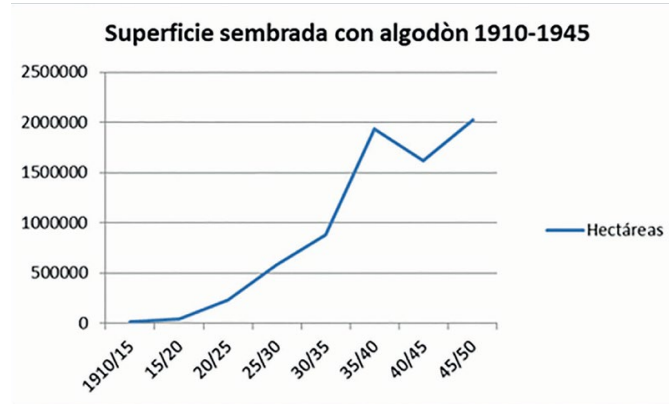

Fuente: elaboración propia base datos de Ferreres, Osvaldo Dos Siglos de Economía Argentina (1810-2004), Fundación Norte y Sur, Bs As, 2005.

En la década del 60, la aparición de las fibras sintéticas, así como el estancamiento del mercado interno, comienza a influir en las ventas y en una correlativa baja de los precios. Se acumulan toneladas de algodón sin colocación, al tiempo que la insuficiente calidad de la fibra local hace difícil su exportación. En el campo, los productores minifundistas ven aumentar sus dificultades, al carecer de superficies en escala adecuada para competir en esa coyuntura, y acumulan deudas. Todo ello llevó a una crisis econó- mica que se manifiesta en toda su crudeza, en la década siguiente, donde la superficie sembrada se reduce en un 30 y aun $40 \%$, pero cuyos signos comienzan a ponerse en evidencia en esta etapa. Durante años, la agricultura dedicó la mayor parte de su actividad a la producción de algodón, convirtiéndolo en el cultivo típico chaqueño. En un segundo plano se ubican la soja, sorgo, arroz, maíz, trigo, maní, tabaco, girasol y hortalizas (ADÁMOLI; TORRELLA; GINZBURG, 2004).

A su vez, tomando en cuenta el manejo de los suelos en este ciclo, pueden apreciarse amplias extensiones bajo cultivo, con graves problemas de declinación de la productividad, debido especialmente a la degradación del recurso tierra (pérdida de nutrientes, de materia orgánica, compactación, etc.) y un ciclo de exceso y déficit hídricos. Estos problemas tienen un impacto mas contundente en la zona de la provincia donde el tamaño de las explotaciones agrícolas es reducido (menores a 25 has), aunque tampoco las grandes explotaciones logran evitar este proceso depredativo. El problema se incrementa en las zonas con ecosistemas frágiles y poco estables (Noroeste y Suroeste de la provincia), donde existen prácticas de cultivos con tecnología no apropiada para el ambiente. A este asunto se debe agregar el sostenido grado de "incineración" de la materia orgánica, sinergizada por una alta tasa de extracción de nutrientes, por algunos cultivos de bajo aporte de materia.

En relación a los impactos ambientales del algodón, el más evidente es el que se produce en los "suelos". En la salinización se combinan tanto factores debidos al relativo mal manejo del suelo, como cuestiones 
físicas y ambientales - aguas salinas, napas freáticas altas, rápida evaporación - que potencian este efecto en el suelo. De igual forma, el bajo contenido de materia orgánica determina menos estructura de los suelos, hecho que facilita una mayor evapotranspiración. En la erosión laminar, la intensidad de las precipitaciones se conjuga con suelos con problemas de drenaje lo cual genera a su vez, un fuerte escurrimiento con el consecuente arrastre de las partículas del suelo. También se relaciona con el exceso de labores y el tipo de labranza vertical entre otros aspectos negativos (BERGAMÍN et al., 2005, p. 78). Debe sumarse además el progresivo desmonte de suelos con escasa aptitud agrícola que impactará de forma sostenida en el estancamiento del desarrollo económico y social de la zona, sumado a una intensa alteración de la biodiversidad natural y de los ambientes mas frágiles (ADÁMOLI; TORRELLA; GINZBURG, 2004).

\section{La expansión agrícola en el Gran Chaco argentino a finales del siglo XX}

Los cambios en el sistema productivo agrario argentino

La llamada "agriculturización" en el nuevo ciclo productivo, se consolidó primero en la pampa húmeda, siendo en los años 80 cuando el proceso empezó a implantarse en otras eco-regiones del país. Allí se trasladaron capitales, tecnologías de producción, parte de la producción de carne bovina y los semilleros-criaderos de granos y forrajeras (MORELLO, 2005, p. 23).
Mapa 2 - Zonas de producción de soja en la Argentina, año 2010

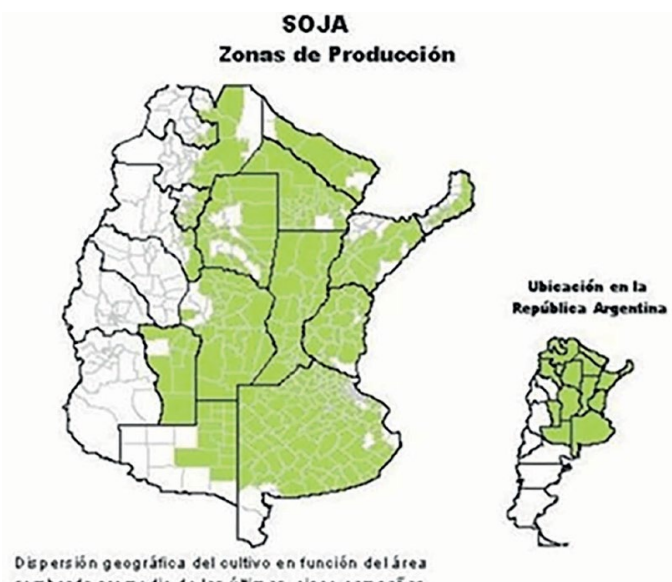
sembrada promedio de las útimas oinco oampañas.

Fuente: Dirección de Coordinación de Delegaciones. Estimaciones Agrícolas. SAGPyA.

En los años 1990 se aceleró fuertemente el proceso de concentración de la tierra y se intensificó la actividad agrícola, tanto en la pampa húmeda como en regiones extra-pampeanas (Noroeste y Noreste). Los censos agropecuarios del Instituto Nacional de Estadística y Censos (INDEC) muestran que entre 1988 y 2002 la superficie media de las explotaciones pasó de 375 a de 509 hectáreas en la provincias pampeanas (PIÑEIRO; VILLARREAL, 2005). Esta concentración productiva ha ido acompañada de una gran transformación agrícola y del incremento sostenido del cultivo de soja. En los últimos años, sólo en la pampa húmeda se han convertido a agricultura casi 7 millones de hectáreas de campo natural o con cultivo forrajero, usados para producción de carne (casi un $15 \%$ del total dedicado a la ganadería). La expansión de la soja ha llevado a una caída de la siembra de maíz de entre un 10 y un $20 \%$, debido a que los costos de producción del maíz son el doble que los de la soja. 
Uno de los cambios cualitativos sustanciales en este contexto es que el eje de la explotación agrícola no está centrado en la propiedad de la tierra, sino en la capacidad del productor-empresario para organizar y coordinar una red de contratos. Aún en los casos de productores que son propietarios de la tierra que trabajan, la estrategia económica y financiera usual es la de un empresario organizador de contratos o "pool de siembra", vinculado con diversos mercados: de capitales para el financiamiento de tierras para el arrendamiento y de servicios en el que los contratistas son los oferentes. Esta estrategia ha favorecido la combinación de sistemas de tenencia de la tierra que tienden a incrementar la superficie trabajada sin que se produzca necesariamente un aumento de escala en su propiedad. En la región central, los contratistas adquirieron gran relevancia a partir de fines de la década de 1980, al ampliarse la demanda de labores agrícolas para las cuales el propietario no posee maquinaria.

No es posible considerar las transformaciones ocurridas en el agro argentino desde las últimas décadas del siglo pasado sin hacer referencia a las grandes diferencias entre las regiones agroecológicas del país, porque la modernización tecnológica y la transformación del mercado interno tuvieron efectos diferentes en las diversas regiones y entre productores y trabajadores. La región pampeana (comprendiendo las provincias de Buenos Aires, Córdoba, Santa Fe y La Pampa) es la que ha provisto la mayor parte de la producción agraria en cuanto a granos y productos ganaderos, y la casi totalidad de las exportaciones agropecuarias (primarias y manufacturadas). Ha resultado particu- larmente favorecida - aunque con fuertes heterogeneidades internas - por las alzas registradas en oleaginosos y algunos cereales, mientras el decrecimiento de los cultivos industriales que se destinaban principalmente al mercado interno (algodón, caña de azúcar o yerba mate, entre otros) afectó las economías regionales no pampeanas, es decir, al resto de las regiones: el Noroeste, el Noreste, Cuyo y la Patagonia. Ello se debió a la creciente importancia del complejo sojero y al incremento de la industria aceitera para la exportación, situación que no ha sido seguida con igual resultado por las producciones regionales en las que se observó un relativo estancamiento, con pocas excepciones.

Más alla de que el área sembrada con soja tiene una amplia dispersión, es en la región del Parque Chaqueño donde se registra su explosiva expansión. Esta dispersión está, además sostenida desde los avances biotecnológicos que posibilitan expandir el cultivo sobre nuevas áreas, en cuanto al valor de la tierra. Mientras que en la zona núcleo (Sur de Córdoba y Santa Fe y Norte de Buenos Aires) los campos oscilan entre los U\$S 6.000 y U\$S 18.000/has; en Salta, Chaco o Santiago del Estero su precio varía entre U\$S 200 y U\$S 1.500/has (MONTENEGRO et al., 2005, p. 9). No resulta entonces casual que el área sembrada en la Pampa Húmeda haya aumentado un $85 \%$ entre las campañas $1997 / 98$ y $2004 / 05$, mientras que en el noroeste lo haya hecho un $220 \%$, en el noreste un $417 \%$ y en otras regiones marginales un $522 \%$ (MERENSON, 2009). Este "complejo sojero" tiene como elementos constitutivos la utilización de semillas mejoradas, agroquímicos y maquinaria de alta capacidad 
operativa, y la continua adopción de los cultivos transgénicos. Más de 150.000 pequeños y medianos productores han desaparecido en poco más de una década al no poder "adaptarse" a esta situación macroeconómica con altos impuestos, elevados precios de los insumos y dependencia de precios inter- nacionales, todas ellas variables fuera de su control. Cerca de 400.000 personas que dependían de la agricultura, no sólo para obtener alimento sino para mantener viva su identidad cultural, han migrado a las grandes ciudades o se mantienen en la pobreza en sus propios predios.

Gráfico 2 - Producción de soja en la República Argentina, 1969-2009

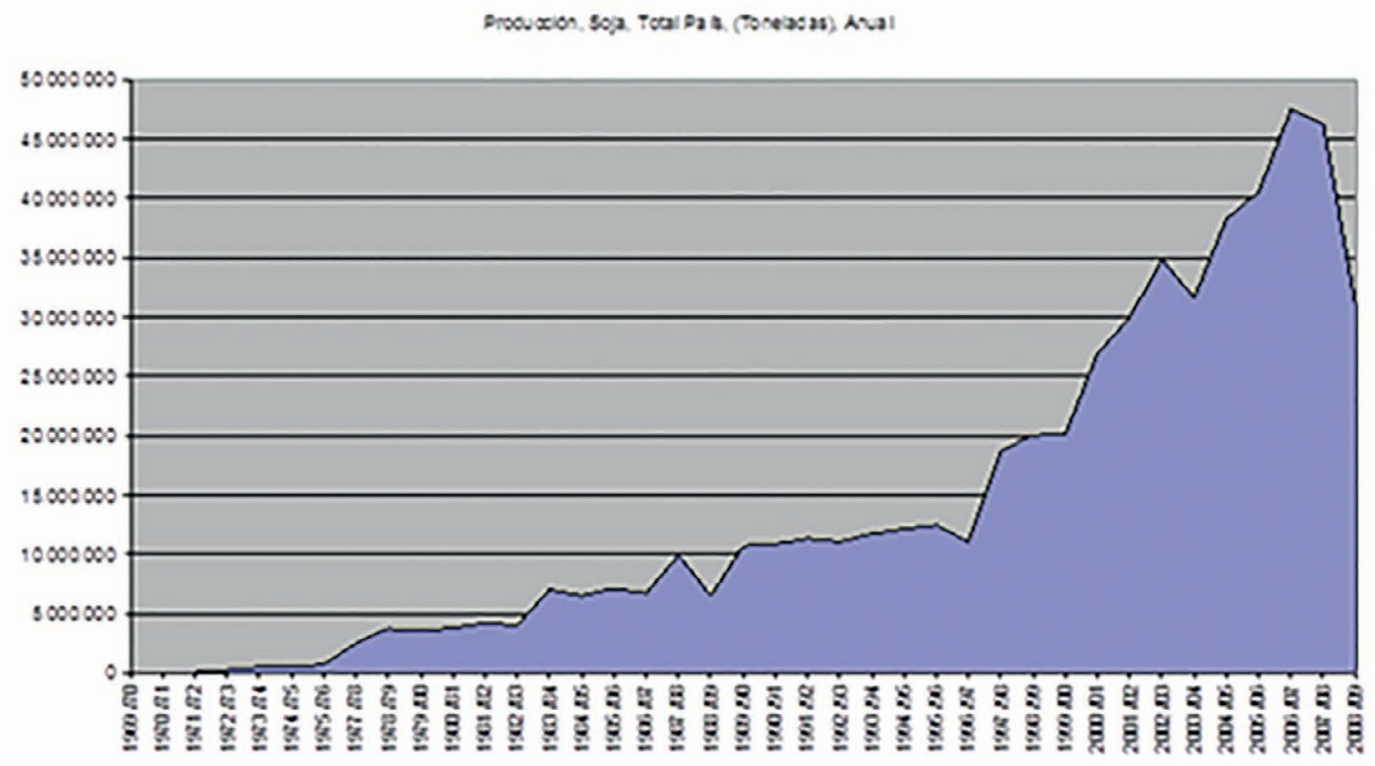

Fuente: elaboración propia en base a Ministerio de Agricultura, Ganadería, Pesca y Alimentación (2009).

Una fecha clave fue 1998 cuando se introdujo la soja OGM o genéticamente modificada, tolerante a los herbicidas, ésta fue rápidamente adoptada por los agricultores argentinos (BRANFORD, 2004, p. 40-43). La resistencia de la soja OGM a los glifosatos facilitó el control de malezas, de modo que para 2002 la adopción de la soja OGM llegó a acercarse al $100 \%$. Además de la pérdida de los hábitats naturales, el explosivo crecimiento del cultivo de soja en Argentina ha tenido otras consecuencias socioeconómicas severas. La producción de alimentos y de lácteos para el mercado nacional se desplomó, en tanto que se incrementó el uso de los agroquímicos, la intoxicación humana y la contaminación del agua. La combinación de crisis económica y expulsión de los pequeños agricultores y de los trabajadores rurales, resultante de la siembra mecanizada de soja, ha disminuido la soberanía alimentaria (MAARTEN DROS, 2004, p. 23). 


\section{El impacto de la producción de soja en el Gran Chaco}

El proceso de expansión agraria analizado en este trabajo está conformado por diversos frentes, localizados principalmente en el Gran Chaco Argentino, y específicamente en la provincia del mismo nombre, donde se observó en la última década la caída radical del cultivo tradicional de la provincia, el algodón, y la fuerte tendencia al monocultivo de soja. Este proceso genera opiniones encontradas y es una creciente fuente de conflictos: por una parte impulsando la incorporación al mercado agrícola de nuevas áreas productivas al mapa productivo del país; por otra parte, implicando un enorme riesgo para la sostenibilidad agraria: simplificación del paisaje, deforestación, pérdida de diversidad biológica y problemas sociales, particularmente la concentración de renta y la disminución del trabajo rural.

Las transformaciones del sector agrícola del Gran Chaco Argentino en los años 90, a partir de la expansión de la soja genéticamente modificada (transgénica, también llamada soja RR) constituyen un ejemplo concreto de estos procesos de desarrollo geográfico desigual y de contra-racionalidades generadas a partir de una nueva racionalidad productiva. Las diferencias socio-ecológicas entre la pampa húmeda y las regiones extra-pampeanas (Noroeste y Noreste de la Argentina) explican las peculiaridades del modelo de desarrollo agrícola de éstas últimas, que deben destacarse al hablar de la "pampeanización" de su agricultura, en otras palabras, la translación indiscriminada del esquema de producción pampeano a regiones periféricas.
Los fenómenos de agriculturización y pampeanización presentan una estructura similar. Si definimos como proceso de agricultura sostenible aquel que:

[...] usa y potencia los recursos naturales de una manera racional, garantizando su protección y recuperación, de tal manera que no se altere el equilibrio ambiental; lo cual asegura así el aprovechamiento permanente de los recursos naturales por muchas generaciones (ESCOBAR, 1995, p. 7-25).

Estos diferentes significados o intensidades apuntan a que las amenazas de insostenibilidad en el caso de las regiones extra-pampeanas son mucho más marcadas.

En primer lugar, en el caso de las regiones extra-pampeanas, los precios relativos de las tierras eran mucho menores que en la Pampa. Esto explica que el avance de la superficie agrícola haya sido muy rápido. Además, este avance no sólo se produjo a costa de otros cultivos sino también a través del desmonte y la eliminación de fragmentos de bosque que sostenían una economía maderera tradicional. Como resultado, la degradación de ecosistemas, servicios ambientales, suelo y agua ha sido mucho más marcada en las provincias del Nordeste que en la región pampeana. Por ejemplo, en el centro del dorsal agrícola de la provincia del Chaco la agricultura ocupa ya el $85 \%$ de un área de 73.311 has, y el mínimo a conservar del antiguo bosque de quebracho colorado, que debería estar entre el 15 y el $25 \%$, presenta ya un elevado nivel de fragmentación.

En segundo lugar, no sólo se desplazaron especies sino población: pequeños campesinos y población indígena que vivía en, y con, los recursos que provee el monte. 
Las transformaciones sociales derivadas de la agriculturización en regiones extra-pampeanas han sido similares: reestructuración social asociada a la concentración económica y productiva. En estas regiones las transformaciones del proceso de trabajo a causa del monocultivo de soja han llevado a un dramático éxodo rural, pérdida de empleo rural y debilitamiento de las comunidades rurales, en muchas ocasiones acompañados de importantes conflictos sociales, como los que se sucedieron en la provincia del Chaco en 2006 y 2007 con el reclamo de las comunidades aborígenes de sus títulos de tierras (BOLSI; PAOLASO; LONGHI, 2006). Es que el proceso de transformación de la estructura productiva que estamos analizando no opera sobre "tierras vacías". Si bien en las primeras etapas el avance del cultivo se sustentó en el reemplazo del uso de las tierras disponibles (sustituyendo otros cultivos, variedades y actividades productivas), cada vez más fue necesitando de nuevas tierras en donde desplegarse. Así, fue avanzando por sobre territorios indígenas y campesinos, lo que ha generado conflictos y disputas, en un marco de relaciones de poder no igualitarias. Generando además crecientes procesos de politización a nivel de organizaciones de base de agricultores y campesinos.

\section{Impactos socio-ambientales del monocultivo sojero}

Además de los conflictos comerciales e impositivos, el monocultivo sojero impuso desequilibrios agroecológicos, como pérdida de capacidad productiva de los suelos, mayor presión de plagas y enfermedades, cambios en la población de malezas, mayor riesgo por contaminación con plaguicidas, etc. Un claro ejemplo es el balance de materia orgánica en el suelo, que en los sistemas agrícolas resulta una función directa de los aportes de los residuos de cosecha, su composición y la tasa de mineralización (BROWN; MARTINEZ ORTIZ; ACERBI Y CORCHERA, 2006). En un monocultivo continuo de soja el balance de materia orgánica tiende a ser negativo, ya que el carbono mineralizado no logra ser compensado con el aportado por los rastrojos de soja, cultivo que se caracteriza por una baja relación C/N. Pensando en el mediano y largo plazo, la sostenibilidad agrícola sólo se puede garantizar con los sistemas diversificados, que preservan el ambiente en general y el suelo en particular mejor que los monocultivos (PENGUE, 2000, p. 108).

Con esta expansión se han puesto en riesgo los espacios donde persisten sistemas productivos tradicionales sostenidos por unidades campesinas, y aquellos donde existe población indígena que mantiene diferentes grados de articulación con las estructuras capitalistas. Migraciones, población rural desempleada, pueblos que se pierden, se contraponen con el paisaje productivista sojero donde dominan las grandes extensiones de tierras cubiertas con trigo/soja y matizadas por sofisticados elementos tecnológicos, como silos, máquinas trilladoras o amplias cubiertas plásticas.

La mayor superficie de bosque nativo se encuentra en la región centro-norte del país. Desde 1999 el trabajo incesante de las máquinas topadoras para el desmonte en las provincias de Santiago del Estero, Cha- 
co, Salta, Tucumán, Formosa, Misiones, Corrientes, Córdoba, Santa Fe y Entre Ríos han creado 2.000.000 nuevas hectáreas de soja. En la región chaqueña, una de las más afectadas, se estima que para 2010 se habrán desmontado unas 4.300.000 has (MONTENEGRO et al., 2005, p. 264).

En cuanto a la población, en la región chaqueña habitan aproximadamente 3.600 .000 personas, el $11 \%$ de la población argentina. De ese porcentaje, prácticamente el $50 \%$ vive en condiciones de pobreza o miseria (MAARTEN DROS, 2004, p. 22). Pero lo más significativo es que el $33 \%$ de la población es todavía rural, y gran parte de esa población, tanto criollos como aborígenes, encuentra amenazada su posibilidad de continuar habitando el territorio. La presencia de esos pequeños productores y comunidades indígenas es muy importante para conservar los bosques y garantizar un desarrollo sustentable (DIRECCIÓN DE BOSQUES, 2004, p. 7).

Uno de los efectos ambientales más importantes de la expansión de la frontera agrícola en el Gran Chaco ha sido la deforestación y degradación del bosque nativo, favorecido a partir de 1980 por la inversión en infraestructura, los avances tecnológicos (cultivos transgénicos y siembra directa) y el contexto internacional de globalización, acentuado desde la década del 90 (ZARRILLI, 2007, p. 235). La deforestación se refiere exclusivamente a la pérdida de superficie forestal, es decir que no mide el grave proceso de "degradación" de las masas forestales restantes. Los bosques nativos de Argentina han sufrido severos procesos de degradación y en muchas partes se encuen- tran comprometidas sus posibilidades de proporcionar bienes y servicios. Esto no significa que hayan perdido su potencial, como se aprecia en el Primer Inventario Nacional de Bosques Nativos.

Teniendo en cuenta que los bosques nativos son fuente de recursos para la población, un indicador útil es la superficie de bosque nativo per cápita. La población de Argentina pasó de aproximadamente 18 millones en 1941 a 36 millones en 2001, mientras la superficie de bosque nativo disminuyó constantemente. En 1940 se disponía de más de 2 ha de bosque nativo por persona y en la actualidad este valor es inferior a 1 ha (DEFELLIPPE, 1945).

En la región chaqueña predomina la pérdida de bosque causada por el avance de la frontera agropecuaria. La tasa de deforestación regional está por encima del promedio mundial y es particularmente alta en los departamentos de la zona húmeda, donde se dan las mejores condiciones para la expansión agrícola. Aún conserva grandes extensiones de bosque continuo, pero en su mayoría en la zona seca. Además de la deforestación, los bosques nativos argentinos padecen severos procesos de degradación que favorecen la pérdida de biomasa y dan como resultado un bosque empobrecido, un deterioro que conduce casi inexorablemente a su desaparición. El caso de Argentina es parte de un proceso general donde la agricultura se está expandiendo a costa de los bosques secos y/o estacionales. 


\section{Reflexión final}

Cómo ya hemos mencionado y comentado, la integración de los ciclos forestal y algodonero chaqueños fue facilitada por la presencia explícita del modelo de agro exportación de materias primas, la región no fue la excepción, la "mancha" ecológica de ambos ciclos es el perfil más visible del modo de explotación.

A la tala indiscriminada del bosque de quebracho que modificó la fisonomía del paisaje (10 millones de hectáreas deforestadas), se le agrega ahora el monocultivo algodonero que necesita aplicar otro desmonte generalizado para incorporar nuevas tierras al proceso económico. El uso del suelo como potencial productivo para los monocultivos y explotación selectiva tiene consecuencias ambientales muy complejas y negativas en el largo plazo. La degradación de los bosques por la explotación destructiva de los mismos; deja una huella en el territorio que no deja rastros de "progreso" perdurables, en todo caso representa un modo específico para la ocupación efectiva del espacio y para la inmigración posterior asociada al cultivo del algodón.

En las dos últimas décadas, la consolidación de un modelo de desarrollo capitalista del agro configurado en torno a la agroindustria exportadora, impulsando cultivos de alta rentabilidad, habilitados para invertir en el uso intensivo de tecnología, fue determinando la inserción de los agricultores en los mercados nacionales e internacionales, acelerando la exclusión de la pequeña agricultura. En el Gran Chaco, estos procesos se sintetizan en la desarticulación definitiva de una lógica territorial y social nacida en la primera mitad del siglo XX, dando paso a la concentración y polarización de la actividad agrícola y la marginación social y expulsión del sistema productivo de los pequeños agricultores.

Esta desarticulación muestra las debilidades estructurales de los sistemas agrícolas locales y su vulnerabilidad. A partir de la crisis de 1999, el desplazamiento del algodón y su impacto en la agricultura provincial, pusieron de manifiesto las consecuencias de la falta de políticas claras, concretas y equilibradas para el sector. A escala regional, la nueva racionalidad productiva supone la inserción subordinada, coyuntural y complementaria de la agricultura chaqueña como periferia ampliada de la frontera productiva pampeana, en un contexto de precariedad que hace prever una "retirada" apresurada ante la disminución de los beneficios temporales. Pero el avance de la soja no es más que el corolario de una problemática más compleja, referida a la mayor vulnerabilidad de las áreas marginales al complejo productivo pampeano. La expansión sojera, a costa de producciones agropecuarias tradicionales, expone crudamente la falta de una política de desarrollo que promueva el manejo sustentable y equilibrado de la actividad agropecuaria y defina el papel de las distintas regiones argentinas.

La implantación exitosa del uso alternativo de la tierra requiere de un cambio de paradigma entre productores, inversores y Estado. Los gobiernos nacionales y provinciales necesitarán del compromiso y el apoyo de los participantes en la producción de soja y su cadena de comercialización, para pro- 
mover prácticas más sustentables. Tanto la adopción de criterios conservacionistas como el establecimiento de lineamientos para los productores - elaborados por un organismo que represente a las múltiples partes implicadas - constituyen un complemento necesario para las medidas legales y técnicas dirigidas a reducir los impactos negativos en los ecosistemas y en las comunidades locales, los sectores más afectados por los cambios producidos. A su vez una característica clave de estos conflictos ha sido la creciente politización horizontal de las comunidades locales, que se constituyeron como un actor político de notable influencia local y regional, chocando la mayoría de las veces con sectores concentrados del poder económico o con autoridades gubernamentales.

\section{Abstract}

In times of independence in the early nineteenth century, it had in Argentina 160 million hectares of forests and jungles. In less than two centuries the country lost more than two thirds of its native forest heritage. Today we are less than 33 million hectares of forest. The exploitation of this extraordinary forest wealth Argentina, is the starting point of this analysis proposed from a historical perspective of environmentally evolution of territorial changes in the Argentine Gran Chaco region, during the twentieth century, their production cycles and their relationship to the expansion of capitalist agriculture model. Our main objective is, then, the historical-environmental study of this process of transformation of this region, in the context of entering the market and the relationship established between this process of deforestation and the expansion of the agricultural frontier, its transformation artificial, conflicts, specialization, rationality, interaction and the progressive deterioration.

Keywords: History. Environment. Gran Chaco.

\section{Resumo}

No tempo da independência, no princípio do século XIX, havia na Argentina 160 milhões de hectares de florestas e matas nativas. Em menos de dois séculos, o país perdeu mais de dois terços de seu patrimônio florestal original. Hoje, restam menos de 33 milhões de hectares com florestas. A exploração dessa extraordinária riqueza florestal argentina é o ponto de partida desta análise, que se propõe a traçar um quadro interpretativo - de uma perspectiva histórico-ambiental - da evolução das transformações histórico-ambientais da região do Grande Chaco argentino no século XX, seus ciclos produtivos e sua relação com a expansão do modelo de agricultura capitalista. O objetivo central é, portanto, o estudo histórico-ambiental do processo de transformação dessa região, no contexto de sua incorporação ao mercado e da relação que se estabelece entre este processo de desmatamento e a expansão da fronteira agrícola, a transformação artificial, os conflitos, os graus de especialização, a racionalidade, a interação e sua deterioração progressiva.

Palavras-chave: História. Ambiente. Grande Chaco. 


\section{Referencias}

ADÁMOLI, Jorge; TORRELLA, Sebastián; GINZBURG, Ruben. Diagnóstico ambiental del chaco argentino. Buenos Aires: Dirección de Conservación del Suelo y Lucha contra la Desertificación; Secretaría de Ambiente y Desarrollo Sustentable, 2004.

BERGAMÍN, G. et al. Impacto socioeconómico y ambiental del monocultivo de algodón. Un enfoque integral para un estudio de caso (Chaco). In: PRIMERAS JORNADAS INTERDISCIPLINARIAS DE ESTUDIOS AGRARIOS Y AGROINDUSTRIALES, 4 y 5 de noviembre. Buenos Aires: Facultad de Ciencias Económicas, Universidad Nacional de Buenos Aires, 2005.

BOLSI, A.; PAOLASSO, P.; LONGHI, F. El Norte Grande Argentino entre el progreso y la pobreza. Población y Sociedad, San Miguel de Tucumán, n. 12-13, p. 227-266, 2006.

BRANFORD, Sue. Argentina's bitter harvest. New Scientist, 17 de abril, p. 40-43, 2004.

BROWN, A. U. M.; MARTINEZ ORTIZ, M.; ACERBI Y CORCHERA, J. Situación Ambiental Argentina 2005. Buenos Aires: Fundación Vida Silvestre, 2006. 587p.

COZZO, Domingo. La Argentina forestal. Buenos Aires: EUDEBA, 1967.

DEFELIPPE, Bernardo. La energía forestal en la República Argentina. Buenos Aires: [s. n.], 1945.

DIRECCIÓN DE BOSQUES. SAyDS, Unidad de Manejo del Sistema de Evaluación Forestal, Estimación de volumen, biomasa y contenido de carbono de las regiones forestales argentinas, sept. 2004.

ESCOBAR, A. Encountering Development. The Making and Unmaking of the Third World. Princeton: Princeton University Press, 1995.

MAARTEN DROS, Jan. Managing the soy boom: two scenarios of soy production expansion in South America. Amsterdam: AIDEnvironment, 2004.
MERENSON, Carlos. Primera estimación del pasivo socio-ambiental de la expansión del monocultivo de soja en Argentina. Ciencia $\mathcal{E}$ Naturaleza, Buenos aires, n. 11, p. 1-7, 2009.

MONTENEGRO, C. et al. Estimación de la pérdida de superficie de bosque nativo y tasa de deforestación en el norte de argentina. Buenos Aires: UMSEF Unidad de Manejo del Sistema de Evaluación Forestal, Dirección Bosques, Secretaría de Ambiente y Desarrollo Sustentable, 2005.

MORELLO, J. Entrando al Chaco con y sin el consentimiento de la Naturaleza. Vida Silvestre, v. 92, p. 23, 2005.

MORELLO, Jorge; PENGUE, Walter; RODRIGUEZ, Alejandra. Etapas de uso de los recursos y desmantelamiento de la biota del Chaco. FAUBA-GEMAPA, UBA, Buenos Aires, n. 4, p. 3-19, 2005.

PENGUE, Walter. Commoditización y diversificación de la producción agropecuaria frente a la oferta biotecnológica argentina: ¿Dos alternativas mutuamente excluyentes?. En: Comisión de Agricultura de la Honorable Camara de Senadores de Buenos Aires. Transgénicos. Biotecnología en el agro. Buenos Aires: Editorial Universitaria de La Plata, 2000. p. 107-124.

PIÑEIRO, M.; VILLARREAL, F. Modernización agrícola y nuevos actores sociales. Ciencia Hoy, Buenos Aires, v. 15, n. 87, p. 32-26, 2005.

TORTORELLI, Lucas. Maderas y bosques argentinos. Buenos Aires: Orientación Gráfica Editora, 1956.

VALENZUELA, Cristina. Factores determinantes de las decisiones agrarias. Consideraciones acerca de los efectos de la estructura fundiaria y la exclusividad productiva en la agricultura chaqueña. Boletín de Estudios Geográficos, Mendoza: Facultad de Filosofía y Letras, Universidad Nacional de Cuyo, n. 96, p. 11-31, 2000. 
ZARRILLI, Adrián. Bosques y agricultura. Una mirada a los límites históricos de sustentabilidad de los bosques argentinos en un contexto de la explotación capitalista en el siglo XX. En: GIRBAL-BLACHA, Noemí M.; MENDONÇA, Sonia Regina (Dir.). Cuestiones agrarias en Argentina y Brasil: conflictos sociales, educación

y medio ambiente. Buenos Aires: Prometeo, 2007. 